\title{
The Habitual Diet of Dutch Adult Patients with Eosinophilic Esophagitis Has Pro-Inflammatory Properties and Low Diet Quality Scores
}

\author{
Marlou L. A. de Kroon 1, ${ }^{\text {, }}$ Simone R. B. M. Eussen ${ }^{2,+}{ }^{\mathbb{D}}$, Bridget A. Holmes ${ }^{3}$, Lucien F. Harthoorn ${ }^{2}$, \\ Marijn J. Warners ${ }^{4}$, Albert J. Bredenoord ${ }^{5}$, Bram D. van Rhijn ${ }^{6}$, Mylene van Doorn ${ }^{2,7}$ \\ and Berber J. Vlieg-Boerstra $8,9, *$ (D)
}

check for

updates

Citation: de Kroon, M.L.A.; Eussen, S.R.B.M.; Holmes, B.A.; Harthoorn, L.F.; Warners, M.J.; Bredenoord, A.J.; van Rhijn, B.D.; van Doorn, M.;

Vlieg-Boerstra, B.J. The Habitual Diet of Dutch Adult Patients with Eosinophilic Esophagitis Has Pro-Inflammatory Properties and Low Diet Quality Scores. Nutrients 2021, 13, 214. https://doi.org/ $10.3390 /$ nu13010214

Received: 10 October 2020 Accepted: 8 January 2021 Published: 13 January 2021

Publisher's Note: MDPI stays neutral with regard to jurisdictional clai$\mathrm{ms}$ in published maps and institutional affiliations.

Copyright: (C) 2021 by the authors. Licensee MDPI, Basel, Switzerland. This article is an open access article distributed under the terms and conditions of the Creative Commons Attribution (CC BY) license (https:// creativecommons.org/licenses/by/ $4.0 /)$.
1 Department of Health Sciences, University Medical Center Groningen, University of Groningen, 9713 GZ Groningen, The Netherlands; m.l.a.de.kroon@umcg.nl

2 Danone Nutricia Research, 3508 TC Utrecht, The Netherlands; simone.eussen@danone.com (S.R.B.M.E.); lucien.harthoorn@clasado.com (L.F.H.); mylenevandoorn@hotmail.com (M.v.D.)

3 Global Nutrition Department, Danone Nutricia Research, 91120 Palaiseau, France; bridgetaholmes@gmail.com

4 Department of Gastroenterology \& Hepatology, Sint Antonius Hospital, 3435 CM Nieuwegein, The Netherlands; m.warners@antoniusziekenhuis.nl

5 Department of Gastroenterology \& Hepatology, Academic Medical Center, 1105 AZ Amsterdam, The Netherlands; a.j.bredenoord@amsterdamumc.nl

6 Department of Dermatology \& Allergology, University Medical Center, 3584 CX Utrecht, The Netherlands; b.d.van.rhijn@gmail.com

7 Division of Human Nutrition, Wageningen University, 6708 WE Wageningen, The Netherlands

8 Department of Pediatrics, OLVG Hospital, 1091 AC Amsterdam, The Netherlands

9 Department of Nutrition \& Dietetics, Hanze University of Applied Sciences, 9747 AS Groningen, The Netherlands

* Correspondence: b.vlieg-boerstra@olvg.nl; Tel.: +31-6-20965-612

$+\quad$ These authors contributed equally to this work.

Abstract: We determined the nutritional adequacy and overall quality of the diets of adult patients with eosinophilic esophagitis (EoE). Dietary intakes stratified by sex and age were compared to Dietary Reference Values (DRV). Overall diet quality was assessed by two independent Diet-QualityIndices scores, the PANDiet and DHD-index, and compared to age- and gender-matched subjects from the general population. Lastly, food and nutrient intakes of EoE patients were compared to intakes of the general population. Saturated fat intake was significantly higher and dietary fiber intake significantly lower than the DRV in both males and females. In males, the DRV were not reached for potassium, magnesium, selenium, and vitamins A and D. In females, the DRV were not reached for iron, sodium, potassium, selenium, and vitamins A, B2, C and D. EoE patients had a significantly lower PANDiet and DHD-index compared to the general population, although the relative intake (per $1000 \mathrm{kcal}$ ) of vegetables/fruits/olives was significantly higher (yet still up to $65 \%$ below the recommended daily amounts) and alcohol intake was significantly lower compared to the general Dutch population. In conclusion, the composition of the habitual diet of adult EoE patients has several pro-inflammatory and thus unfavorable immunomodulatory properties, just as the general Dutch population, and EoE patients had lower overall diet quality scores than the general population. Due to the observational character of this study, further research is needed to explore whether this contributes to the development and progression of EoE.

Keywords: diet; diet quality; food intakes; adults; eosinophilic esophagitis

\section{Introduction}

Eosinophilic esophagitis (EoE) is a chronic, immune-mediated condition of the esophagus affecting both adults and children [1,2]. Although the exact pathogenic mechanism 
of the disease remains to be elucidated, exposure of the esophagus to foods and aeroallergens in genetically predisposed subjects is suggested to influence the development of the disease [3-6]. Foods most commonly implicated in EoE are cow's milk, egg, soy, wheat or gluten, legumes, fish/shellfish and nuts/peanuts [4,7-9]. Disease remission can be accomplished by using topical corticosteroids or proton-pump inhibitors (PPIs), or by the dietary elimination of food allergens proven to trigger EoE $[1,6,9,10]$. Both elimination diets as well as elemental diets have shown remarkable clinical and histological responses in adults with EoE [9,11,12]. Additionally, many individuals with EoE adapt their eating behavior by chewing their foods very carefully, taking small bites, consuming more beverages with a meal, and eating foods with a softer consistency $[13,14]$.

Besides the fact that food allergens can trigger an allergic reaction in EoE, in a previous study it was hypothesized that healthy and immune-enhancing nutrition may either be protective against the development of EoE or, in contrast, unhealthy nutrition may facilitate the development of food allergy through its impact on inflammation and esophageal mucosal integrity [15]. However, hardly any data have been published about dietary composition in EoE patients. In a cross-sectional study in adults with EoE, we recently showed that high intakes of dietary fiber, iron, fermented dairy (buttermilk, Lactobacillus rhamnosus GG-containing yoghurt drink), dairy, pasta/rice, and soy were negatively related to the degree of inflammation and positively related to mucosal integrity in EoE patients. In contrast, phosphorus (abundant in animal-based foods), high intakes of omega6 rich oil (sunflower and/or stir fry oil), and total added fat had a positive relationship with inflammation and a negative relationship with mucosal integrity [15].

To further study the nutritional quality of the habitual diet in EoE, the present study aims were threefold: (1) to compare the nutrient intakes of Dutch adult patients with EoE with Dutch Dietary Reference Values (DRV) by age and sex; (2) to compare the overall diet quality of EoE patients with diet quality of the general Dutch population by using Diet Quality Indices (DQI), and (3) to compare the food and nutrient intakes of EoE patients with intakes of the general Dutch population. The study was performed prior to any elimination diets other than self-imposed dietary measures. DQI provide a single score for a combination of foods and/or nutrients, based on current nutrition knowledge established in food or nutrient based dietary guidelines [16-18]. Since foods and nutrients are consumed in combination and may interact with each other, DQI can be used when investigating diet-disease associations [16-18].

\section{Materials and Methods}

\subsection{Study Population}

Adult patients diagnosed with active EoE ( $\geq 15$ eosinophils/high power field (HPF) and symptoms of esophageal dysfunction), who participated in two trials (Trialregister.nl NTR4052 and NTR4892) performed in the Academic Medical Center, Amsterdam, the Netherlands, were included between 2013 and 2015. Patients participating in Trial NTR4052 followed an allergen-microarray-guided dietary intervention as treatment of EoE [19]. Patients participating in Trial NTR4892 were treated with an elemental diet for four weeks $[9,20]$. From these two studies, baseline data, i.e., before starting any (elimination) diet other than self-imposed dietary measures, were used in the present study. Information on atopic status and food avoidance was collected by medical and allergy focused diet history.

\subsection{Dietary Intake Assessment}

All patients completed a 3-day non-weighed food diary ( 2 working days and 1 weekend day) as described previously (online supporting information in [15]). In short: Patients recorded amounts of foods and drinks in detail as well as dietary supplements (type, yes/no, infrequently). Portion size was assessed using household measures. The average of the 3-day diaries (without supplements) was calculated using the Dutch NEVO-online Food Composition Database [21] and Evry software [22] for energy (kcal) and 32 nutrients 
(Supplementary Table S1). Additionally, all foods consumed were allocated to one of 38 food groups, based on the Dutch National Food Consumption Survey (DNFCS) [23] (see Supplementary Table S1).

\subsubsection{Dutch Dietary Reference Values}

The 3-day mean habitual intake of nutrients, stratified for age group and gender, was compared to the Dutch DRV for males and females [24-26].

\subsubsection{Overall Diet Quality}

For each patient, two DQIs were calculated from the dietary data, i.e., the Probability of Adequate Nutrient intake (PANDiet) [27] and the Dutch Healthy Diet Index (DHDindex) [28]. Since the PANDiet score is based on nutritional recommendations (i.e., the intake of macro- and micronutrients) and the DHD-index on food based dietary guidelines (i.e., intakes of fruit, vegetables, fish, etc.), the scores were selected to complement each other.

\subsubsection{PANDiet}

The PANDiet is a nutrient-based DQI which measures the adequacy of intake of 25 macro- and micronutrients in comparison to nutritional recommendations: protein, total fat, saturated fatty acids (SFA), linoleic acid (LA), $\alpha$-linolenic acid (ALA), the sum of eicosapentaenoic acid (EPA) and docosahexaenoic acid (DHA), total carbohydrate, dietary fiber, vitamins $\mathrm{A}, \mathrm{B} 1, \mathrm{~B} 2, \mathrm{~B} 6, \mathrm{~B} 12, \mathrm{C}, \mathrm{D}, \mathrm{E}$, calcium, copper, iodine, iron, magnesium, potassium, selenium, sodium, and zinc [29]. Further details of the PANDiet and its validation in the general Dutch population can be found in Supplementary File S1.

\subsubsection{DHD-Index}

The DHD-index is a DQI that ranks participants according to their adherence to food based dietary guidelines, i.e., in the Netherlands, the Dutch Guidelines for a Healthy Diet of 2006 [30]. These guidelines consist of ten components (i.e., physical activity and the intake of vegetables, fruit (juices), fiber, fish, saturated fatty acids (SFA), trans fatty acids, acidic drinks and foods, sodium and alcohol) which are divided into adequacy components and moderation components. The DHD-index was previously (2012) validated in the general Dutch population [28]. Further details of the DHD-index and its application to the present study can be found in Supplementary File S1.

\subsection{Data from the General Dutch Population}

The 3-day average habitual intake of foods and nutrients in EoE patients, stratified by age group and gender, was compared to reference intakes of males 18 to 69 years $(n=1114)$ and females 18 to 50 years $(n=763$, according to the classification of the Dutch National Food Consumption Survey (DNFCS, 2007-2010) [23]. The average dietary assessment in the DNFCS was based on two non-consecutive 24-hour dietary recalls per subject, using the Dutch NEVO-online Food Consumption Database [23]. Nutrient intakes from supplements were not assessed.

\subsection{Statistical Analyses}

Descriptive statistics were used to summarize findings. All data were checked for normality using Shapiro-Wilk tests and histograms. Normally distributed data were presented as means and standard deviations (SD). Skewed data were presented as medians with interquartile ranges (IQR). Categorical data were reported as $n$ with percentages of total. To compare dietary intake with the DRV for adults, according to age and sex, skewed data were log-transformed prior to analyses. One-tailed Student's $t$-tests were performed to test whether dietary intake of the different nutrients were significantly lower (at $p=0.05$ ) or significantly higher (at $p=0.05$ ) than the reference value (given by the DRV), based on the hypothesis that the intake of the tested nutrient would be unhealthier 
than recommended. For example: we tested if the fat intake was significantly higher in EoE patients than the maximum recommended intake; however, for most nutrients we tested whether this intake was significantly lower than recommended (some examples are calcium, and vitamins A, C and D). The results were presented as the mean and the upper bound or lower bound of the $95 \%$ confidence interval (CI) (if it was tested if the intake of a nutrient was significantly lower and higher than recommended, respectively) on the original (back-transformed) scale.

The DQI scores of EoE patients were compared to the scores of the general Dutch population using an independent two-tailed samples $t$-test. Patient characteristics were compared between the EoE patients and the general Dutch population using independent samples $t$-tests or Mann-Whitney $U$ tests. Food and nutrient intakes between the EoE patients and the general Dutch population were compared using Mann-Whitney U tests. These comparisons were made after the intakes of nutrients were corrected for energy intakes (consumption per $1000 \mathrm{kcal} /$ day), because energy intake in men of 31-50 years differed significantly between the two groups. Statistical analyses were performed using SAS Enterprise Guide v.6.1 and IBM SPSS Statistics v.20.0. $p$-Values of $<0.05$ were considered statistically significant.

\section{Results}

\subsection{Patient Characteristics}

Baseline characteristics of the 34 EoE patients were presented previously (Table 1, adapted from [15]). In short, the majority of EoE patients (79\%) reported having one or more concomitant atopic diseases. Sixty-two percent of the patients reported to have one or more food allergies, including pollen-food syndrome (previously known as Oral Allergy Syndrome). Nineteen patients (56\%) avoided specific foods: 12 (35\%) because of pollen-food syndrome, 7 (21\%) because of food allergy other than pollen-food syndrome and $12(35 \%)$ due to dysphagia, food impaction or dyspepsia. The most frequently avoided food groups were fruit, $n=13(38 \%)$, nuts/peanut/seeds, $n=13(38 \%)$ and vegetables, $n=4$ $(12 \%)$ [15]. Twenty-nine percent of the patients (all male) took dietary supplements, however patients changed brands and types frequently. Age and BMI of EoE patients and the general Dutch population were comparable [23]. However, among EoE patients, a higher percentage was male $(76.5 \%$ versus $59 \%, p=0.041)$.

Table 1. Patient characteristics of Eosinophilic esophagitis (EoE) patients $(n=34)$ at baseline.

\begin{tabular}{|c|c|}
\hline$n(\%)$ or Median; IQR & \\
\hline Male gender in $\%(n=34)$ & $26 / 34(77)$ \\
\hline Age in years: median; IQR $(n=34)$ & $45.2 ; 29.0-49.3$ \\
\hline BMI $(\mathrm{kg} / \mathrm{m} 2)$ : median; IQR $(n=34)$ & $24.7 ; 21.0-26.6$ \\
\hline Atopic disease in $\%(n=34)$ & $27 / 34(79)$ \\
\hline - Atopic dermatitis & $7 / 34(21)$ \\
\hline - Asthma & $14 / 34(41)$ \\
\hline - Allergic rhinitis & $17 / 34(50)$ \\
\hline - Food allergy & $21 / 34(62)$ \\
\hline$\bigcirc$ of which oral allergy symptoms & $17 / 34(50)$ \\
\hline \multicolumn{2}{|l|}{ Food avoidance in $\%(n=34)$} \\
\hline Food groups avoided because of pollen-food syndrome, food allergy or EoE- & $19 / 34(56)$ \\
\hline Food groups avoided because of pollen-food syndrome: & $12 / 34(35)$ \\
\hline - one or more types of fruit & $2 / 34(6)$ \\
\hline - one or more types of nuts/peanut/seeds/legumes & $2 / 34(6)$ \\
\hline - one or more types of fruits/vegetables and nuts/peanut/seeds/legumes & $8 / 34(24)$ \\
\hline Food groups avoided because of other food allergy: & $7 / 34(21)$ \\
\hline - one or more types of fruits/vegetables & $3 / 34(9)$ \\
\hline - one or more types of nuts/peanut/seeds & $3 / 34(9)$ \\
\hline - fish & $1 / 34(3)$ \\
\hline - buckwheat & $1 / 34(3)$ \\
\hline - cow's milk & $1 / 34(3)$ \\
\hline
\end{tabular}


Table 1. Cont.

\begin{tabular}{|c|c|}
\hline$n(\%)$ or Median; IQR & \\
\hline $\begin{array}{l}\text { Food groups avoided because of EoE (dysphagia, impaction or dyspepsia): } \\
\text { - one or more types of nuts/peanut/seeds } \\
\text { - one or more types of fruits/vegetables } \\
\text { - alcoholic beverages } \\
\text { - dairy } \\
\text { - meat } \\
\text { - fish } \\
\text { - egg } \\
\text { - gluten } \\
\text { - bread }\end{array}$ & $\begin{array}{l}12 / 34(35) \\
7 / 34(21) \\
7 / 34(21) \\
5 / 34(15) \\
3 / 34(9) \\
3 / 34(9) \\
2 / 34(6) \\
2 / 34(6) \\
2 / 34(6) \\
1 / 34(3)\end{array}$ \\
\hline $\begin{array}{l}\text { Use of supplements in } \%(n=34) \\
\text { - taken on a regular basis } \\
\text { - taken on an irregular basis } \\
\text { - no supplements } \\
\text { - unknown or unclear }\end{array}$ & $\begin{array}{c}8 / 34(23) \\
2 / 34(6) \\
20 / 34(59) \\
4 / 34(12)\end{array}$ \\
\hline $\begin{array}{l}\text { Baseline measures of eosophageal inflammation (Peak eosinophil count/HPF): } \\
\text { median; IQR }(n=34)\end{array}$ & $40 ; 29-80$ \\
\hline
\end{tabular}

\subsection{Comparison to Dietary Reference Values}

Table 2 shows that the average percentage of energy (en\%) from protein, carbohydrates and total fat in EoE patients was in line with dietary guidelines, although protein and total fat intakes were relatively high. Intake of saturated fat was significantly higher than the DRV (below $10 \mathrm{en} \%$ ) in males $(13.2 \mathrm{en} \% ; p<0.001)$, whereas dietary fiber intake was significantly lower than the DRV $(30 \mathrm{~g} / \mathrm{d})$; both in males $(19.6 \mathrm{~g} / \mathrm{d} ; p<0.001)$ and females $(18.3 \mathrm{~g} / \mathrm{d} ; p=0.014)$. In males, the majority of micronutrient intake levels were in line with the recommended daily amounts with the exception of significantly lower intakes of potassium ( $3020 \mathrm{vs.} 3500 \mathrm{mg} / \mathrm{d} ; p=0.005)$, magnesium ( $311 \mathrm{vs.} 350 \mathrm{mg} / \mathrm{d} ; p=0.026)$, selenium (44.5 vs. $60 \mu \mathrm{g} / \mathrm{d} ; p<0.001)$, vitamin A (414 vs. $900 \mu \mathrm{g} \mathrm{RE} / \mathrm{d} ; p<0.001)$ and vitamin $\mathrm{D}(2.1$ vs. $10 \mu \mathrm{g} / \mathrm{d} ; p<0.001)$. Females had significantly lower intakes than the DRV of a larger number of nutrients (i.e., iron ( $10.1 \mathrm{vs.} 16 \mathrm{mg} / \mathrm{d} ; p=0.024)$, sodium (1788 vs. $2400 \mathrm{mg} / \mathrm{d} ; p=0.027)$, potassium $(2794$ vs. $3500 \mathrm{mg} / \mathrm{d} ; p=0.020)$, selenium ( $34.5 \mathrm{vs}$. $50 \mu \mathrm{g} / \mathrm{d} ; p<0.001$ ), vitamins A (405 vs. $680 \mu \mathrm{g} \mathrm{RE} / \mathrm{d} ; p=0.007), \mathrm{B} 2$ (1.3 vs. $1.6 \mathrm{mg} / \mathrm{d}$; $p=0.004), C(40.8$ vs. $75 \mathrm{mg} / \mathrm{d} ; p=0.009)$ and $\mathrm{D}(2.4$ vs. $10 \mu \mathrm{g} / \mathrm{d} ; p=0.002)$. 


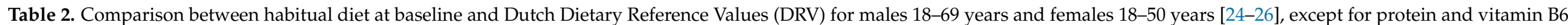
where different DRVs apply for 18-50-year-old and >50-year-old males and comparisons are only presented for males and females 18-50 years.

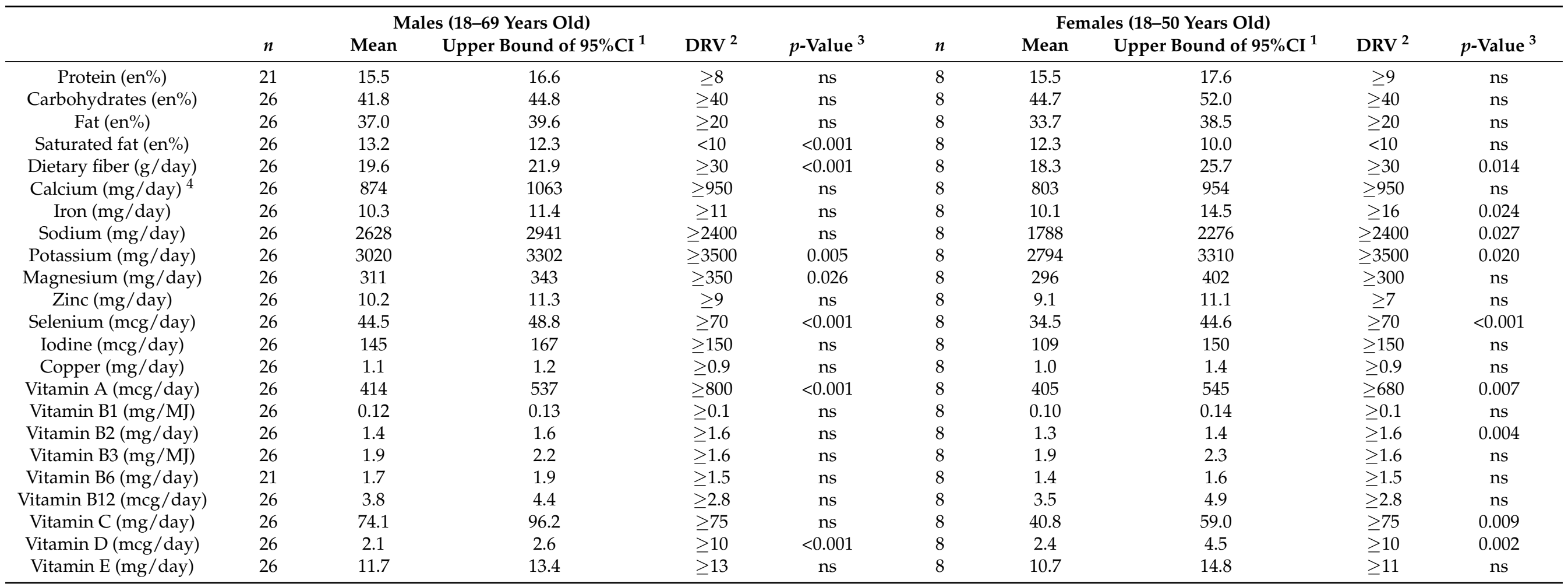

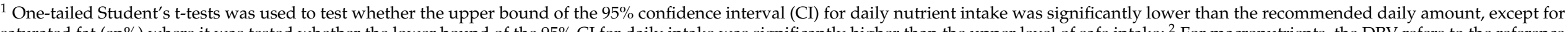

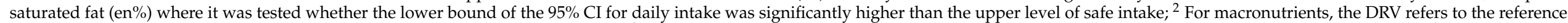

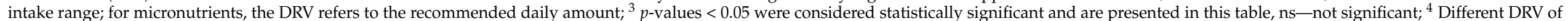
calcium apply for $18-24$ years vs. $\geq 25$ years. Due to the low number of patients $<25$ years ( $n=1$ for males; $n=3$ for females), DRV for $\geq 25$ years was taken for the whole population. 


\subsection{Diet Quality Indices}

Table 3 shows that the PANDiet and DHD-index of the EoE patients and the general Dutch population were statistically significantly different, with the EoE patients having lower DQI scores compared to the general Dutch population.

Table 3. Comparison of Diet Quality Index scores between EoE patients and the general Dutch population.

\begin{tabular}{cccccccc}
\hline & & EoE & \multicolumn{5}{c}{ DNFCS 2007-2010 } \\
& $\boldsymbol{n}$ & Mean & SD & $\boldsymbol{n}$ & Mean & SD & $p$-Value \\
\hline PANDiet & 34 & 57.0 & 8.7 & 1877 & 61.1 & 7.3 & $0.001^{*}$ \\
DHD-index & 34 & 47.1 & 12.1 & 1877 & 50.9 & 10.4 & $0.032 *$ \\
\hline
\end{tabular}

EoE-eosinophilic esophagitis, DNFCS—Dutch National Food Consumption Survey, SD—-standard deviation, PANDiet-Probability of Adequate Nutrient intake, DHD-index-Dutch Healthy Diet Index; $p$-values were obtained from independent two-tailed samples $t$-test. ${ }^{*} p$-values $<0.05$ are given in bold.

\subsection{Comparison of Intake by EoE Patients with Intake by the General Dutch Population}

Male EoE patients had lower energy intakes than the general Dutch population: EoE males $(n=26)$, median $2228 \mathrm{kcal} /$ day, IQR $1709-2556$, vs. the general population $(n=1114)$, median $2582 \mathrm{kcal} /$ day, IQR 2131-3088, $p=0.003$. However, for the different age groups these differences were not statistically significant, except for males aged 18-30 years. For EoE women, there were no statistically significant differences in energy intake.

After correction for energy intake, male EoE patients had a statistically significantly higher energy percentage from fat and had lower intakes of omega-3 fatty acids (EPA and DHA), vitamin D and alcohol per $1000 \mathrm{kcal}$, while female EoE patients had lower intakes of omega-3 fatty acids, iodine and vitamin C per $1000 \mathrm{kcal}$ than the general Dutch population (Table 4) [23].

In Table 5 it is shown that after correction for energy intake, male EoE patients consumed significantly more vegetables, fruit/nuts/olives, egg/egg products and miscellaneous food groups and, in contrast, less alcoholic beverages and added fat than the general Dutch population. Female EoE patients consumed more potatoes/other tubers, vegetables and fewer non-alcoholic beverages. 


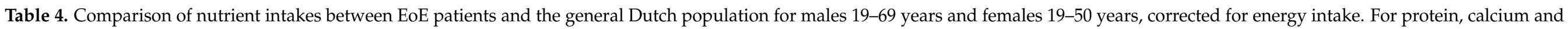
vitamin B6 comparisons are only presented for males and females 19-50 years old. Nutrient intakes are shown per 1000 kcal.

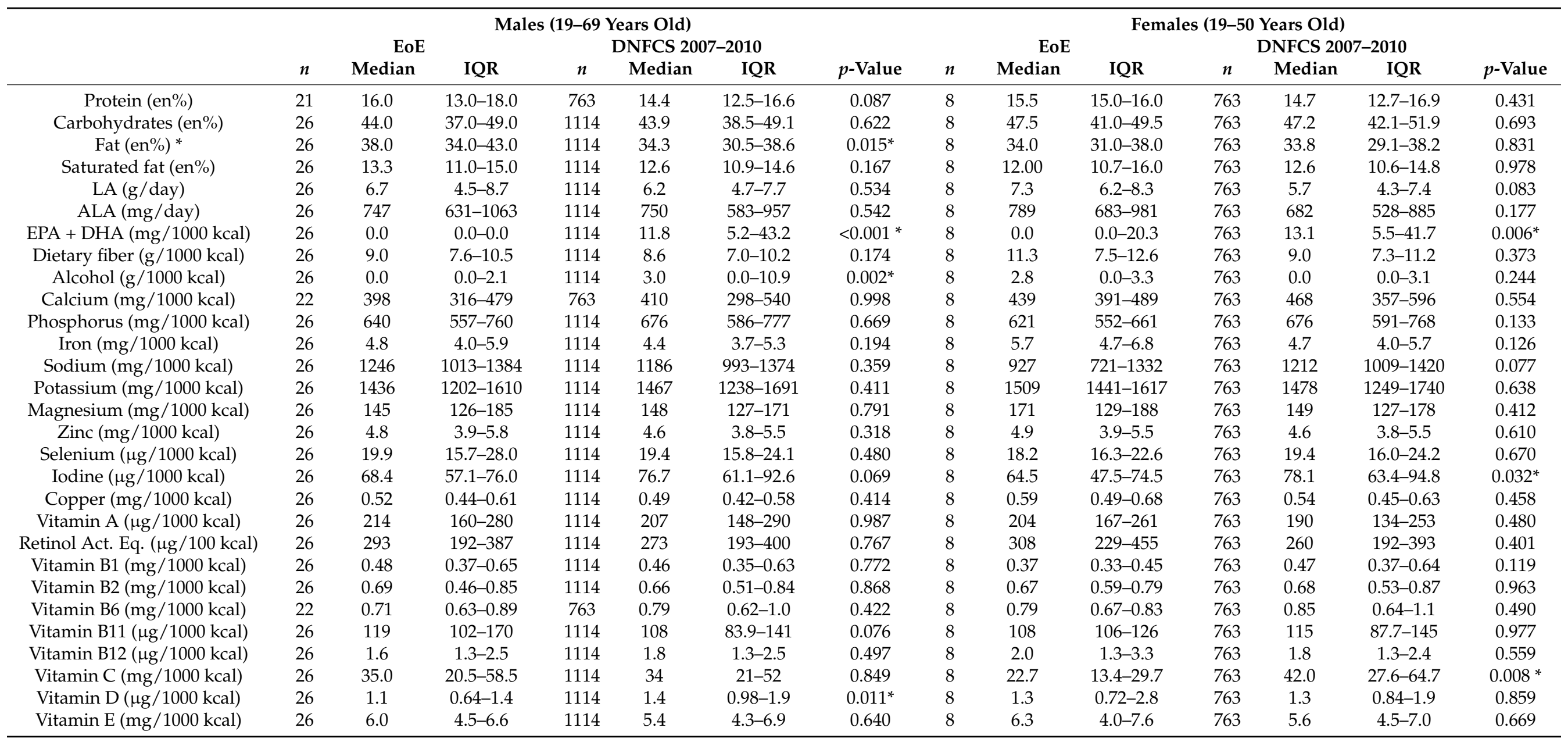

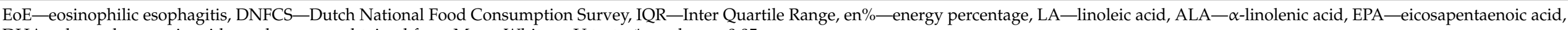

DHA—docosahexaenoic acid; $p$-values were obtained from Mann-Whitney $\mathrm{U}$ tests. * $p$-values $<0.05$ 
Table 5. Comparison of the intake of different food groups (in grams per 1000 kcal) between EoE patients and the general Dutch population.

\begin{tabular}{|c|c|c|c|c|c|c|c|c|c|c|c|c|c|c|}
\hline & \multicolumn{7}{|c|}{ Males (19-69 Years Old) } & \multicolumn{7}{|c|}{ Females (19-50 Years Old) } \\
\hline & \multirow[b]{2}{*}{$n$} & \multicolumn{2}{|c|}{ EoE } & \multicolumn{3}{|c|}{ DNFCS 2007-2010 } & \multirow[b]{2}{*}{$p$-Value } & \multicolumn{3}{|c|}{ EoE } & \multicolumn{3}{|c|}{ DNFCS $2007-2010$} & \multirow[b]{2}{*}{$p$-Value } \\
\hline & & Median & IQR & $n$ & Median & IQR & & $n$ & Median & IQR & $n$ & Median & IQR & \\
\hline Potatoes and tubers & 26 & 29.0 & $0.0-50.9$ & 1114 & 39.3 & $15.3-67.4$ & 0.153 & 8 & 55.8 & $48.6-63.2$ & 763 & 32.6 & $0.0-57.0$ & 0.025 * \\
\hline Legumes & 26 & 0.0 & $0.0-0.0$ & 1114 & 0.0 & $0.0-0.0$ & 0.953 & 8 & 0.0 & $0.0-0.0$ & 763 & 0.0 & $0.0-0.0$ & 0.480 \\
\hline Fruit, nuts and olives & 26 & 44.1 & $23.1-88.5$ & 1114 & 26.6 & $1.7-62.5$ & 0.031 & 8 & 53.3 & $16.9-71.7$ & 763 & 38.5 & $4.6-83.8$ & 0.704 \\
\hline Fruit & 26 & 35.5 & $9.9-77.4$ & 1114 & 22.6 & $0.0-56.1$ & 0.054 & 8 & 52.5 & $16.9-63.2$ & 762 & 35.7 & $0.0-80.1$ & 0.634 \\
\hline Dairy products & 26 & 124.1 & 68.3-191 & 1114 & 137.9 & $70.0-223$ & 0.638 & 8 & 126.3 & $92.0-237.4$ & 763 & 144.8 & $82.1-228$ & 0.973 \\
\hline Meat and meat products & 26 & 50.8 & $30.2-69.4$ & 1114 & 46.8 & $30.3-67.4$ & 0.751 & 8 & 35.5 & $12.1-73.5$ & 763 & 42.7 & $23.9-61.6$ & 0.795 \\
\hline Fish and shellfish & 26 & 0.0 & $0.0-5.2$ & 1114 & 0.0 & $0.0-2.9$ & 0.971 & 8 & 0.0 & $0.0-14.9$ & 763 & 0.0 & $0.0-1.3$ & 0.860 \\
\hline Eggs and egg products & 26 & 3.7 & $0.0-15.4$ & 1114 & 0.0 & $0.0-7.7$ & $0.046^{*}$ & 8 & 0.0 & $0.0-6.2$ & 763 & 0.0 & $0.0-7.7$ & 0.800 \\
\hline Added fat & 26 & 7.2 & $3.5-11.7$ & 1114 & 12.0 & $7.2-16.7$ & $0.007 *$ & 8 & 9.2 & $4.6-12.7$ & 763 & 9.6 & $5.6-14.4$ & 0.742 \\
\hline Sugar and confectionery & 26 & 9.8 & $3.4-26.7$ & 1114 & 14.6 & $5.0-26.6$ & 0.416 & 8 & 17.4 & $6.4-19.9$ & 763 & 15.6 & $6.2-29.7$ & 0.618 \\
\hline Cakes & 26 & 9.6 & $0.0-22.2$ & 1114 & 12.0 & $0.0-26.2$ & 0.605 & 8 & 20.8 & $3.7-34.7$ & 763 & 17.8 & $4.8-34.2$ & 0.945 \\
\hline Non-alcoholic beverages & 26 & 473.8 & $284-735$ & 1114 & 584.0 & $435-831$ & 0.115 & 8 & 555.6 & $516-673$ & 763 & 857.7 & $651-1208$ & 0.004 * \\
\hline Alcoholic beverages & 26 & 0.0 & $0.0-30.8$ & 1114 & 42.5 & $0.0-166$ & 0.003 * & 8 & 28.4 & $0.0-42.1$ & 763 & 0.0 & $0.0-28.1$ & 0.171 \\
\hline Condiments and sauces & 26 & 10.2 & $4.9-16.0$ & 1114 & 11.1 & $4.9-20.5$ & 0.478 & 8 & 8.6 & $5.5-12.3$ & 763 & 10.7 & $4.5-20.1$ & 0.454 \\
\hline Miscellaneous & 26 & 10.9 & $0.0-26.0$ & 1114 & 0.0 & $0.0-8.5$ & $<0.001$ * & 8 & 0.0 & $0.0-7.1$ & 763 & 0.0 & $0.0-10.6$ & 0.821 \\
\hline
\end{tabular}

EoE—eosinophilic esophagitis, DNFCS—Dutch National Food Consumption Survey, IQR—Inter Quartile Range; $p$-values were obtained from Mann-Whitney U tests. * $p$-values $<0.05$. 


\section{Discussion}

EoE is an emerging chronic disease, affecting individuals at any age with a predominance for Caucasian males under the age of 50 [31]. To our knowledge, this is the first study in which the nutritional adequacy and overall diet quality of the habitual diets of adult patients with EoE, prior to any elimination diets other than self-imposed dietary measures, have been assessed by diet scores. In addition, this study is the first in which intake data of adult patients with EoE were compared to those of the general population. In a previous study, we were able to find a relationship between nutrition and the degree of inflammation and mucosal integrity in EoE patients, pointing towards a possible protective effect of a healthy diet consisting of more dietary fiber, fermented dairy and plant-based foods and less fat, animal foods and omega-6-rich oil [15].

In the current study, we showed that for several nutrients, the intake of adult EoE patients did not meet the DRV. Among the nutrients that were statistically significantly different from the DRV, there were several nutrients known for their beneficial or adverse effect on the microbiome, immune system, inflammation or mucosal integrity. For example, the high intake of (saturated) fat in EoE patients is likely to induce a shift in microbiome composition associated with inflammatory processes [32,33]. In addition, intakes of total fat and protein in EoE patients, although within the DRV range, were relatively high, which has been shown to negatively impact the microbiome and inflammatory processes as well [32,34]. These findings point towards a high intake of animal foods, typical for a Western diet. In addition, the low intake of dietary fiber in EoE patients is unfavorable for a healthy gut microbiota [35]. The colonic fermentation of dietary fiber results in the production of short chain fatty acids, which have anti-inflammatory and immune-regulatory benefits [36,37], and are important for the maintenance of the epithelial integrity [38]. Moreover, the vitamin A metabolite, retinoic acid, and the vitamin D metabolite, 1,25dihydroxyvitamin D3, have direct effects on immune cells, i.e., by enhancing the induction of regulatory T cells and by controlling Th1 and Th17 differentiation [39,40]. Both vitamins A and D, as well as vitamin C, selenium and iron are recognized by the European Food Safety Authority (EFSA) for their local and systemic immunomodulatory properties [41]. Intakes of these nutrients were low in male and/or female EoE patients and may induce a disbalance in their immune system.

Nutritional deficiencies might gain relevance in EoE. There are a few studies on nutritional deficiencies in EoE patients, predominantly in children [42]. In this systematic review, it was found that vitamin D levels of children with EoE, both pre- and postintervention, were low. One study in adults [43] found that positive skin prick test reaction to peanut was more common in patients who had vitamin D insufficiency (adjusted odds ratio 7.57; $p=0.009$ ). However, higher vitamin $\mathrm{D}$ levels correlated with higher histologic eosinophil counts $(R=0.61 ; p=0.03)$.

When comparing the diet composition of our study population to intake levels of the general Dutch population, male EoE patients had significantly lower energy intakes. After correction for energy intake, we found that intakes of several of the nutrients were different between EoE patients and the general Dutch population. EoE patients (males and/or females) had higher total fat intakes and lower intakes of vitamins $C$ and $\mathrm{D}$ (all $p<0.05$ ). Moreover, EoE patients had lower intake of omega-3 fatty acids. These differences all point towards a diet which has higher pro-inflammatory, lower anti-inflammatory and unfavorable immunomodulatory properties, and overall seems less healthy. Although a significant percentage of EoE patients avoided fruit/vegetables due to pollen-food syndrome, food allergy or EoE symptoms, EoE patients still had a higher relative intake of well-tolerated fruits and vegetables (per $1000 \mathrm{kcal}$ ) compared to the general Dutch population. However, fruit and vegetable consumption in both groups was far below (up to $65 \%$ ) the recommended daily amounts. Remarkably, male EoE patients used less alcohol than male subjects from the general Dutch population. This may be due to the pain and discomfort caused by alcohol in EoE. 
Both DQI scores revealed that EoE patients consumed a less healthy diet compared to the general Dutch population. For the PANDiet score, the lower overall diet quality can be explained by differences in nutrient intakes between the two populations (i.e., in total fat, omega-3 fatty acids, iodine and vitamins $C$ and D). The difference in DHD-index score might be explained by differences in the intake of fatty acids. In EoE patients, the intake of total fat was higher, and the intake of omega-3 fatty acids was lower than in the general Dutch population, which led to a lower DHD-index in EoE patients. In contrast to fruits and vegetables that were avoided by half of the EoE patients due to pollen-food syndrome, food allergy or EoE, only few patients (9\%) avoided the intake of fish [15], thereby only limitedly contributing to the explanation for the low intake of this food group in the EoE patients.

The differences in DQI scores between the total EoE patient population and the general Dutch population might also partly be explained by a difference in energy intake. Overall, the subjects in the general Dutch population had a higher mean energy intake than the EoE patients, which may have contributed to a better diet quality in the general population as individuals with a higher total energy consumption will meet the requirements for specific nutrients or food groups more easily [17].

The strengths of this study include the use of a detailed, standardized way of recording diet history and the fact that, in addition to the assessment of individual nutrient and food intakes, we used DQI scores to assess the overall diet quality of EoE patients. DQI scores examine the effects of the overall dietary pattern and represent a broader picture of food and nutrient intakes as the combination of foods and nutrients in complex eating patterns and their potential synergistic effects are taken into account. The use of DQI scores may therefore be more predictive of disease risk/severity than individual foods or nutrients. The findings of this study are in line with our previous findings on the relationship between habitual diet and severity of disease in the same study population [15].

Possible limitations of the present study are the small sample size of the EoE population (especially low numbers of females), the fact that we did not take into account the potential influence of self-imposed dietary measures due to food allergy or EoE symptoms on food and nutrient intakes, the differences in timeframes between the dietary assessment of the general Dutch population (between 2007-2010) and the EoE patients (between 2013-2015) and the cross-sectional design of the study. The latter hampers the ability to draw conclusions about the causal relationship between diet quality and disease risk and severity. Large prospective cohort studies or intervention studies are needed to assess if there is a causal relationship between diet quality and EoE. Moreover, the dietary intake of the EoE patients was assessed by a 3-day food record. It is known that the dietary intake of individuals may vary from day to day, and hence the intake of infrequently consumed foods such as fish, may be underestimated.

We did not correct for multiple comparisons in our analyses, due to the explorative character of this study. However, although after correction several significant comparisons will lose significance, the main conclusion of our findings remains intact, namely that the diet of EoE patients has several pro-inflammatory properties, just as the diet of the general Dutch population.

Lastly, as in the DNFCS, we did not calculate the intake of supplements, because of the inconsistent use of amounts and types of supplements by patients, which may have influenced disease outcomes.

In conclusion, intakes of dietary fiber and several micronutrients were below the DRV, while intakes of saturated fat were higher than the DRV in adult patients suffering from EoE. Total protein and total fat intakes were relatively high, yet within the range of the DRV, pointing towards a high intake of animal-based foods. Compared to the general Dutch population, the overall diet of EoE patients, as assessed by two independent diet quality scores, was generally less healthy than the diet of the Dutch population, with the exception of the relative intakes (per $1000 \mathrm{kcal}$ ) of vegetables/fruits/olives which were significantly higher (yet still far below (up to 65\%) the recommended daily amounts) and the relative 
intake of alcohol which was significantly lower. Thus, the habitual dietary intake of Dutch adult EoE patients has several pro-inflammatory and unfavorable immunomodulatory properties. These results support the hypothesis that an unhealthy diet is associated with development and progression of EoE. The results of this study are complementary to the results of our recently published cross-sectional study in this population [15].

We are unable to determine whether the diet is changed because of the disease, or that an unhealthy diet precedes the development of EoE. Further prospective and interventional studies are needed to demonstrate causal relationships and effects of diet on the development of EoE. Once the relationship between nutrition and EoE has been established, anti-inflammatory nutrition advice about which foods and nutrients to include and which to avoid could be provided in order to prevent and maintain remission in EoE.

Supplementary Materials: The following are available online at https:/ / www.mdpi.com/2072-664 3/13/1/214/s1, Table S1. Nutrients calculated on the basis of 3-day food diaries and distribution of food groups used. File S1. Calculation and validation of the Diet Quality Indices (DQI).

Author Contributions: Conceptualization, L.F.H. and B.J.V.-B.; methodology, M.L.A.d.K., S.R.B.M.E., M.J.W., M.v.D. and B.J.V.-B.; formal analysis, M.L.A.d.K. and M.v.D.; investigation M.L.A.d.K., S.R.B.M.E. and B.J.V.-B., writing-original draft preparation, M.L.A.d.K., M.v.D. and S.R.B.M.E.; writing-review and editing, M.L.A.d.K., S.R.B.M.E., B.A.H., L.F.H., M.J.W., A.J.B., B.D.v.R., M.v.D. and B.J.V.-B.; supervision, L.F.H. and B.J.V.-B. All authors have read and agreed to the published version of the manuscript.

Funding: B.J.V.-B received funding from Nutricia Research for nutritional analyses.

Institutional Review Board Statement: The study was conducted according to the guidelines of the Declaration of Helsinki, and approved by the Institutional Review Board AMC (NL42608.018.12 and NL49502.018.14).

Informed Consent Statement: Informed consent was obtained from all subjects involved in the study.

Data Availability Statement: The data presented in this study are available on request from the corresponding author. A data sharing agreement will be requested.

Acknowledgments: The authors would like to thank the patients for their willingness to participate in the involved studies.

Conflicts of Interest: S.R.B.M.E., B.A.H. * , L.F.H. ${ }^{*}$ and M.L.A.v.D.* are ( ${ }^{*}$ former) employees of Danone Nutricia Research. A.J.B. received research funding from Nutricia, Norgine, SST and Bayer and received speaker and/or consulting fees from Laborie, Arena, EsoCap, Medtronic, Falk Pharma, Calypso Biotech, Gossamer, Robarts, Reckett Benkiser, Regeneron, AstraZeneca and holds equity interests in SST. B.J.V.-B. received research funding from Nutricia Research for nutritional analyses and received speaker fee from Nutricia and Mead Johnson.

\section{References}

1. Liacouras, C.A.; Furuta, G.T.; Hirano, I.; Atkins, D.; Attwood, S.E.; Bonis, P.A.; Burks, A.W.; Chehade, M.; Collins, M.H.; Dellon, E.S.; et al. Eosinophilic esophagitis: Updated consensus recommendations for children and adults. J. Allergy Clin. Immunol. 2011, 128, 3-20.e26. [CrossRef] [PubMed]

2. Straumann, A.; Spichtin, H.P.; Grize, L.; Bucher, K.A.; Beglinger, C.; Simon, H.U. Natural history of primary eosinophilic esophagitis: A follow-up of 30 adult patients for up to 11.5 years. Gastroenterology 2003, 125, 1660-1669. [CrossRef] [PubMed]

3. Ahmed, M. Eosinophilic esophagitis in adults: An update. World J. Gastrointest. Pharmacol. Ther. 2016, 7, 207-213. [CrossRef] [PubMed]

4. Chehade, M.; Aceves, S.S. Food allergy and eosinophilic esophagitis. Curr. Opin. Allergy Clin. Immunol. 2010, 10, 231-237. [CrossRef] [PubMed]

5. Erwin, E.A.; James, H.R.; Gutekunst, H.M.; Russo, J.M.; Kelleher, K.J.; Platts-Mills, T.A.E. Serum IgE measurement and detection of food allergy in pediatric patients with eosinophilic esophagitis. Ann. Allergy Asthma Immunol 2010, 104, 496-502. [CrossRef]

6. Spergel, J.M. Eosinophilic esophagitis in adults and children: Evidence for a food allergy component in many patients. Curr. Opin. Allergy Clin. Immunol. 2007, 7, 274-278. [CrossRef] [PubMed]

7. Furuta, G.T.; Liacouras, C.A.; Collins, M.H.; Gupta, S.K.; Justinich, C.; Putnam, P.E.; Bonis, P.; Hassall, E.; Straumann, A.; Rothenberg, M.E. Eosinophilic Esophagitis in Children and Adults: A Systematic Review and Consensus Recommendations for Diagnosis and Treatment. Gastroenterology 2007, 133, 1342-1363. [CrossRef] 
8. $\quad$ Spergel, J.M.; Andrews, T.; Brown-Whitehorn, T.F.; Beausoleil, J.L.; Liacouras, C.A. Treatment of eosinophilic esophagitis with specific food elimination diet directed by a combination of skin prick and patch tests. Ann. Allergy Asthma Immunol. 2005, 95, 336-343. [CrossRef]

9. Warners, M.J.; Vlieg-Boerstra, B.J.; Verheij, J.; van Rhijn, B.D.; Van Ampting, M.T.; Harthoorn, L.F.; de Jonge, W.J.; Smout, A.J.; Bredenoord, A.J. Elemental diet decreases inflammation and improves symptoms in adult eosinophilic oesophagitis patients. Aliment Pharmacol. Ther. 2017, 45, 777-787. [CrossRef]

10. Liacouras, C.A.; Spergel, J.M.; Ruchelli, E.; Verma, R.; Mascarenhas, M.; Semeao, E.; Flick, J.; Kelly, J.; Brown-Whitehorn, T.; Mamula, P.; et al. Eosinophilic esophagitis: A 10-year experience in 381 children. Clin. Gastroenterol. Hepatol. 2005, 3, $1198-1206$. [CrossRef]

11. Warners, M.J.; Vlieg-Boerstra, B.J.; Bredenoord, A.J. Elimination and elemental diet therapy in eosinophilic oesophagitis. Best Pract. Res. Clin. Gastroenterol. 2015, 29, 793-803. [CrossRef] [PubMed]

12. Molina-Infante, J.; Arias, A.; Barrio, J.; Rodriguez-Sanchez, J.; Sanchez-Cazalilla, M.; Lucendo, A.J. Four-food group elimination diet for adult eosinophilic esophagitis: A prospective multicenter study. J. Allergy Clin. Immunol. 2014, 134, 1093-1099.e1. [CrossRef]

13. Alexander, R.; Alexander, J.A.; Ravi, K.; Geno, D.; Tholen, C.; Mara, K.; Katzka, D.A. Measurement of Observed Eating Behaviors in Patients With Active and Inactive Eosinophilic Esophagitis. Clin. Gastroenterol. Hepatol. 2019, 17, 2371-2373. [CrossRef] [PubMed]

14. Schoepfer, A.; Safroneeva, E. Activity assessment of eosinophilic esophagitis. Dig. Dis. 2014, 32, 98-101. [CrossRef] [PubMed]

15. de Kroon, M.L.A.; Warners, M.J.; van Ampting, M.T.J.; Harthoorn, L.F.; Bredenoord, A.J.; van Doorn, M.; Kok, M.; van Rhijn, B.D.; Eussen, S.; Vlieg-Boerstra, B.J. The relationship of habitual diet with esophageal inflammation and integrity in eosinophilic esophagitis. Allergy 2019, 74, 1005-1009. [CrossRef] [PubMed]

16. Kourlaba, G.; Panagiotakos, D.B. Dietary quality indices and human health: A review. Maturitas 2009, 62, 1-8. [CrossRef]

17. Waijers, P.M.; Feskens, E.J.; Ocké, M.C. A critical review of predefined diet quality scores. Br. J. Nutr. 2007, 97, 219-231. [CrossRef]

18. Wirt, A.; Collins, C.E. Diet quality—what is it and does it matter? Public Health Nutr. 2009, 12, 2473-2492. [CrossRef]

19. van Rhijn, B.D.; Vlieg-Boerstra, B.J.; Versteeg, S.A.; Akkerdaas, J.H.; van Ree, R.; Terreehorst, I.; Sprikkelman, A.B.; Verheij, J.; Smout, A.J.; Bredenoord, A.J. Evaluation of allergen-microarray-guided dietary intervention as treatment of eosinophilic esophagitis. J. Allergy Clin. Immunol. 2015, 136, 1095-1097.e3. [CrossRef]

20. Warners, M.J.; Vlieg-Boerstra, B.J.; Verheij, J.; van Hamersveld, P.H.P.; van Rhijn, B.D.; Van Ampting, M.T.J.; Harthoorn, L.F.; de Jonge, W.J.; Smout, A.; Bredenoord, A.J. Esophageal and Small Intestinal Mucosal Integrity in Eosinophilic Esophagitis and Response to an Elemental Diet. Am. J. Gastroenterol. 2017, 112, 1061-1071. [CrossRef]

21. National Institute for Public Health and the Environment. NEVO online. Dutch Food Composition Database. Available online: http:/ / nevo-online.rivm.nl/ (accessed on 12 August 2020).

22. Evry. Available online: http:/ / evry.nl/index.php/homemenuitem/dietetiek (accessed on 12 August 2020).

23. van Rossum, C.T.M.; Fransen, H.P.; Verkaik-Kloosterman, J.; Buurma-Rethans, E.J.M.; Ocké, M.C. Dutch National Food Consumption Survey 2007-2010. Diet of Children and Adults Aged 7 to 69 years; National Institute for Public Health and the Environment: Bilthoven, The Netherlands, 2011.

24. Gezondheidsraad. Voedingsnormen: Energie, Eiwitten, Vetten en Verteerbare Koolhydraten; 18 July 2001. Available online: https:/ /www.gezondheidsraad.nl/documenten/adviezen/2001/07/18/voedingsnormen-energie-eiwitten-vetten-enverteerbare-koolhydraten (accessed on 11 January 2021).

25. Gezondheidsraad. Voedingsnormen voor Vitamines en Mineralen voor Volwassenen; 18 September 2018. Available online: https:/ / www.gezondheidsraad.nl/documenten/adviezen/2018/09/18/gezondheidsraad-herziet-voedingsnormen-voorvolwassenen (accessed on 11 January 2021).

26. Brink, E.J.; Breedveld, B.C.; Peters, J.A.C. Aanbevelingen voor Vitamines, Mineralen en Spoorelementen-Factsheet; Voedingscentrum: The Hague, The Netherlands, 2014.

27. Verger, E.O.; Mariotti, F.; Holmes, B.A.; Paineau, D.; Huneau, J.F. Evaluation of a Diet Quality Index Based on the Probability of Adequate Nutrient Intake (PANDiet) Using National French and US Dietary Surveys. PLoS ONE 2012, 7, e42155. [CrossRef] [PubMed]

28. van Lee, L.; Geelen, A.; van Huysduynen, E.J.C.H.; de Vries, J.H.M.; van't Veer, P.; Feskens, E.J.M. The Dutch Healthy Diet index (DHD-index): An instrument to measure adherence to the Dutch Guidelines for a Healthy Diet. Nutr. J. 2012, 11, 49. [CrossRef] [PubMed]

29. Bianchi, C.M.; Mariotti, F.; Verger, E.O.; Huneau, J.F. Pregnancy Requires Major Changes in the Quality of the Diet for Nutritional Adequacy: Simulations in the French and the United States Populations. PLoS ONE 2016, 11, e0149858. [CrossRef] [PubMed]

30. Gezondheidsraad. Richtlijnen Goede Voeding 2006, Publicatie nr 2006/21. Available online: https:/ / www.gezondheidsraad.nl/ documenten/adviezen/2006/12/18/richtlijnen-goede-voeding-2006 (accessed on 11 January 2021).

31. Dellon, E.S. Epidemiology of Eosinophilic Esophagitis. Gastroenterol. Clin. N. Am. 2014, 43, 201-218. [CrossRef] [PubMed]

32. Singh, R.K.; Chang, H.W.; Yan, D.; Lee, K.M.; Ucmak, D.; Wong, K.; Abrouk, M.; Farahnik, B.; Nakamura, M.; Zhu, T.H.; et al. Influence of diet on the gut microbiome and implications for human health. J. Transl. Med. 2017, 15, 73. [CrossRef]

33. David, L.A.; Maurice, C.F.; Carmody, R.N.; Gootenberg, D.B.; Button, J.E.; Wolfe, B.E.; Ling, A.V.; Devlin, A.S.; Varma, Y.; Fischbach, M.A.; et al. Diet rapidly and reproducibly alters the human gut microbiome. Nature 2014, 505, 559-563. [CrossRef] 
34. Zhernakova, A.; Kurilshikov, A.; Bonder, M.J.; Tigchelaar, E.F.; Schirmer, M.; Vatanen, T.; Mujagic, Z.; Vila, A.V.; Falony, G.; Vieira-Silva, S.; et al. Population-based metagenomics analysis reveals markers for gut microbiome composition and diversity. Science 2016, 352, 565-569. [CrossRef]

35. O'Grady, J.; O'Connor, E.M.; Shanahan, F. Review article: Dietary fibre in the era of microbiome science. Aliment Pharmacol. Ther. 2019, 49, 506-515. [CrossRef]

36. Salonen, A.; de Vos, W.M. Impact of diet on human intestinal microbiota and health. Annu. Rev. Food Sci. Technol. 2014, 5, $239-262$. [CrossRef]

37. Vinolo, M.A.; Rodrigues, H.G.; Nachbar, R.T.; Curi, R. Regulation of inflammation by short chain fatty acids. Nutrients 2011, 3, 858-876. [CrossRef]

38. Tilg, H.; Moschen, A.R. Food, immunity, and the microbiome. Gastroenterology 2015, 148, 1107-1119. [CrossRef] [PubMed]

39. Brown, C.C.; Noelle, R.J. Seeing through the dark: New insights into the immune regulatory functions of vitamin A. Eur. J. Immunol. 2015, 45, 1287-1295. [CrossRef]

40. Wintergerst, E.S.; Maggini, S.; Hornig, D.H. Contribution of selected vitamins and trace elements to immune function. Ann. Nutr. Metab. 2007, 51, 301-323. [CrossRef]

41. EFSA NDA Panel (EFSA Panel on Dietetic Products Nutrition and Allergies). Guidance on the scientific requirements for health claims related to the immune system, the gastrointestinal tract and defence against pathogenic microorganisms. EFSA J. 2016, 14, 4369. [CrossRef]

42. Fissinger, A.; Mages, K.C.; Solomon, A.B. Vitamin deficiencies in pediatric eosinophilic esophagitis: A systematic review. Pediatr. Allergy Immunol. 2020, 31, 835-840. [CrossRef] [PubMed]

43. Slack, M.A.; Ogbogu, P.U.; Phillips, G.; Platts-Mills, T.A.; Erwin, E.A. Serum vitamin D levels in a cohort of adult and pediatric patients with eosinophilic esophagitis. Ann. Allergy Asthma Immunol. 2015, 115, 45-50. [CrossRef] 